\title{
New aspects of metrology of frictional behaviour in metal cutting
}

\author{
Nowe aspekty pomiaru tarcia w skrawaniu metali
}

\author{
JOËL RECH \\ CHRISTOPHE CLAUDIN \\ PATRICK POLLY \\ CÉDRIC COURBON *
}

DOI: 10.17814/mechanik.2016.11.520

This paper introduces a method for a fast identification of friction and heat partition models in cutting. Based on a special tribometer able to simulate wide ranges of contact pressures and sliding velocities, the method is applied for a wide spectrum of work materials and lubrication conditions. KEYWORDS: cutting, friction, heat partition

Artykuł wprowadza nową metodę szybkiej identyfikacji modeli tarcia i partycji ciepła w skrawaniu. Umożliwia to symulacja w szerokim zakresie nacisków kontaktowych i szybkości poślizgu z wykorzystaniem specjalnego tribometru. Metoda może być stosowana do szerokiego spektrum materiałów i warunków smarowania.

SŁOWA KLUCZOWE: skrawanie, tarcie, partycja ciepła

\section{Introduction}

One of the ways for improving machining processes is the development of numerical cutting models in order to predict the best cutting conditions and/or the best cutting tool design, which can provide significant enhancement of cutting performance. The key idea is to predict the 'optimal' thermo-mechanical conditions occurring at the tool-work material interface model to improve the tool wear resistance and/or the surface integrity/fatigue life of the final product. Several papers have recently proposed important contributions to the numerical modelling of cutting processes [1, 2]. The development of a numerical cutting model requires a large number of parameters. Among these data, the scientific community still regrets an important lack of knowledge on friction and heat partition models $[3,4]$, especially due to the growing developments in the field of tool materials, tool coatings, as well as in the emerging alternative lubrication techniques, such as cryogenic machining.

Many authors, such as [5], use the cutting process itself to evaluate an average macroscopic value of friction coefficient on the rake face, through cutting force measurements. In parall el, some authors, such as [2, 6], use temperature measurements in cutting to estimate an average heat partition coefficient. Unfortunately, machining tests are only able to provide macroscopic data. Therefore, it is very difficult to discriminate the role of the primary shear zone, of the secondary shear zone, and of the cutting tool edge. To overcome this limitation, inverse methods based

\footnotetext{
* Prof. Joël Rech (joel.rech@enise.fr), Christophe Claudin (christophe. claudin@enise.fr), Patrick Polly (patrick.polly@enise.fr), Cédric Courbon (cedric.courbon@enise.fr) - University of Lyon, Ecole Nationale d'Ingénieurs de Saint-Etienne, LTDS, CNRS UMR5513, 58 rue Jean Parot, 42023 Saint-Etienne, France
}

on either analytical or numerical simulations are usually employed. But due to strong assumptions (ex: constant friction and heat partition coefficients along the contact, etc.), as well as large uncertainties in the work material flow stress models [4], a proper characterisation cannot be performed. Indeed, [4] have shown a strong variation of friction coefficient along the tool-work material contact length owing to the sliding velocity and contact pressure gradients. So, it is very difficult to obtain reliable data on friction and heat partition from machining tests itself.

As concluded by [4], a better understanding of the frictional phenomena at the tool-work material interface can be achieved by using dedicated tribometers, independent of any cutting process, but able to simulate similar tribological conditions (pressure, temperature, and velocity) as those occurring along the tool-work material interface in cutting. However, standard pin-on-disc tribometers are not suitable to simulate incessant freshly generated surface (open tribosystem) in cutting processes. With this in mind, an original experimental set-up [7] has been recently presented, which can be seen as an orthogonal cutting operation on a disc with an extreme negative rake angle. However, only a single rotation of the workpiece is possible before start rubbing against the already deformed surface, which leads to really short friction times and as a consequence does not provide information about heat partition coefficients. As an alternative, [8] has proposed an open tribometer able to simulate contact conditions encountered in cutting on a longer time scale (Fig. 1). In addition to friction coefficient, this tribometer also provides, through a thermal instrumentation, an estimation of the heat partition. By the usage of this tribometer, the objective of this paper is to bring an overview on friction and heat partition coefficients evolution for several key tool-work material pairs under a wide variety of sliding velocities and lubrication conditions (emulsion, straight oil and cryogenic) that are of strategic importance for the development of cutting processes numerical modelling. The influence of contact pressure needs further research and so will not be in detail analysed in this paper. In order to identify more accurate friction and heat partition models, an analytical post-treatment methodology will be presented. Finally it will be shown how these models may improve the efficiency of a numerical cutting simulation.

\section{Experimental set-up}

The tribometer is mounted on a CNC lathe (Fig. 1(a)). The friction at the cutting tool / machined material interface is estimated by the friction of a pin having a spherical geometry (Figs. 1(b) \& 1(c)) made of a similar grade as 
cutting tool that rubs against a cylindrical bar made of the same grade as the machined material. In order to eliminate the potential influence of surface roughness, pins and work material are ground and polished (Ra 0.3 $\mu \mathrm{m}$ similar to a cutting tool). After each friction test, a cutting tool refreshes the surface ploughed by the pin, to remove the affected layer of work material. Each friction test lasts minimum 10 seconds in order to obtain a stationary thermal situation.
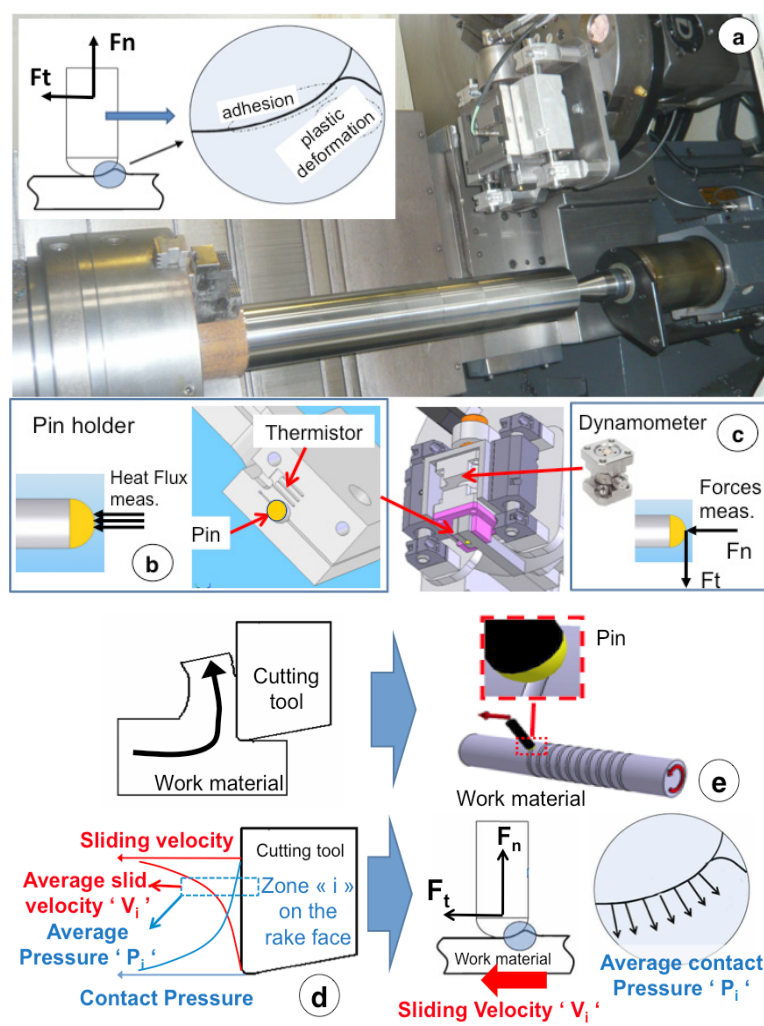

Fig. 1. Description of proposed alternative tribometer and selection of testing conditions in accordance with local friction conditions in cutting

The pin-holder is fixed onto a dynamometer (Fig. 1(c)) in order to provide the normal $\left(F_{n}\right)$ and tangential $\left(F_{t}\right)$ force (macroscopic forces). The desired normal force is assured with controllable hydraulic piston. The apparent friction coefficient (i.e. macroscopic friction coefficient) is provided by their ratio:

$$
\mu_{\text {app }}=\frac{F_{\mathrm{t}}}{F_{\mathrm{n}}}
$$

The term 'apparent friction coefficient' is used since it can slightly differ from the 'interfacial friction coefficient', induced by adhesion at the pin-work material interface. Those macroscopic forces measured by the tribometer include on the one hand adhesive phenomena that are affected by properties such as hardness, chemical reactivity and asperities, while on the other hand plastic deformation of the work material occurs, which cannot be neglected under the severe contact conditions induced by this tribometer. An analytical model presented in [9] enables to extract the interfacial friction coefficient.

Additionally, pins are fixed on a thermally instrumented pin-holder (Fig.1(b)) so that, during a test, the temperature of a thermistor, located very close to the pin spherical face, is measured. The heat flux transmitted to the pin $\left(f_{\text {pin }}\right)$ is quantified by means of an inverse method presented in [8].

It should be underlined that only a percentage of the total frictional energy $f_{\text {tot }}$, dissipated during friction tests, is transmitted to pin. A large amount of the heat remains in the work material as shown in [8]. The total energy dissipated during the test can be estimated by:

$$
\varphi_{\text {tot }}=F_{\mathrm{t}} \cdot V_{\mathrm{s}}
$$

where $V_{s}$ represents the macroscopic sliding velocity in the contact.

Theoretically, the heat partition coefficient $(\alpha)$ that represents the portion of heat flux transmitted to the pin corresponds to:

$$
\dot{a}=\frac{\phi_{\text {pin }}}{\phi_{\text {tot }}}
$$

Concerning the friction conditions that have to be tested, they depend on the one hand on the cutting conditions (feed rate, cutting speed, etc.), and on the other hand on the position along the tool-work material contact area. Indeed, since [4, 10], Fig. 1(d) reminds that sliding velocity varies along the tool-work material interface and differs on the rake face and on the flank face due to the chip compression ratio. Low sliding velocities are consistent with local sliding velocities close to the cutting edge radius, whereas high sliding velocities are consistent with local sliding velocities at the end of the tool-work material interface on rake and flank faces. For instance, if industry is willing to machine an Inconel718 alloy with a TiN coated carbide tool and cutting speeds up to $100 \mathrm{~m} / \mathrm{min}$, it is necessary to conduct friction tests with TiN coated carbide pins and sliding velocities in the range 5 to $100 \mathrm{~m} / \mathrm{min}$.

Regarding contact pressure, it can be adjusted independently of the sliding velocity by changing pin's diameter and/or normal force $F_{n}$. For instance, when cutting Inconel718 alloys with TiN coated carbide tools, the local contact pressure along the tool-work material interface can vary from 0 to $3 \mathrm{GPa}$. This maximum contact pressure, mainly encountered close to the cutting edge radius, can be achieved with a $\varnothing 9 \mathrm{~mm}$ spherical pin and a $1000 \mathrm{~N}$ normal force (Fig. 1(e)). This contact pressure can be assessed by the model presented in [8].

Next paragraph will be devoted to show the ability of this tribometer to quantify rapidly a friction and heat partition models versus sliding velocity for a large range of work material and lubrication conditions.

\section{Influence of work material and lubrication}

Fig. 2 enables to have a comparable overview on the frictional behaviour of various work materials with a widely used TiN coated carbide tool. Part of the results have already been published in [8, 11-14], whereas others are original ones.

All tests have been conducted with the maximum average contact pressure that can be reached for each material pair. The average contact pressure is reported on each curve. Each testing conditions have been replicated at least three times. The average deviation is maximum $\pm 15 \%$.

This figure reveals that apparent friction coefficients $\mu$ app can vary significantly (i.e. from 0.1 to about 0.7 ). Moreover, friction coefficient decreases significantly with sliding velocity. When sliding velocity increases, almost all apparent friction coefficients of metallic work materials are around 0.2 in dry conditions, which corresponds to a semi-solid frictional regime as assumed by [4]. This 


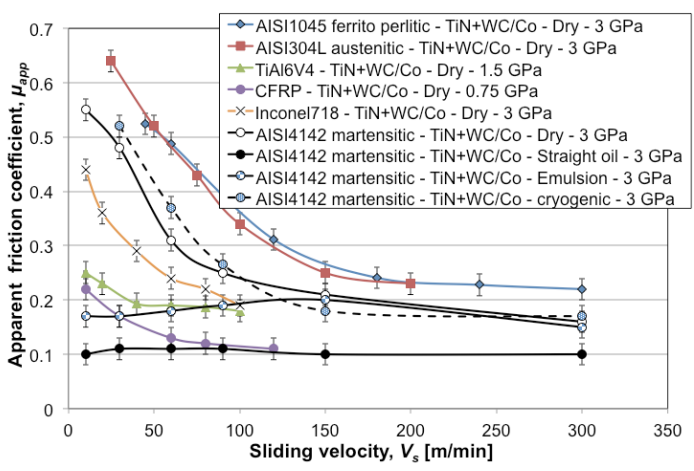

Fig. 2. Evolution of apparent friction coefficient versus sliding velocity for various material

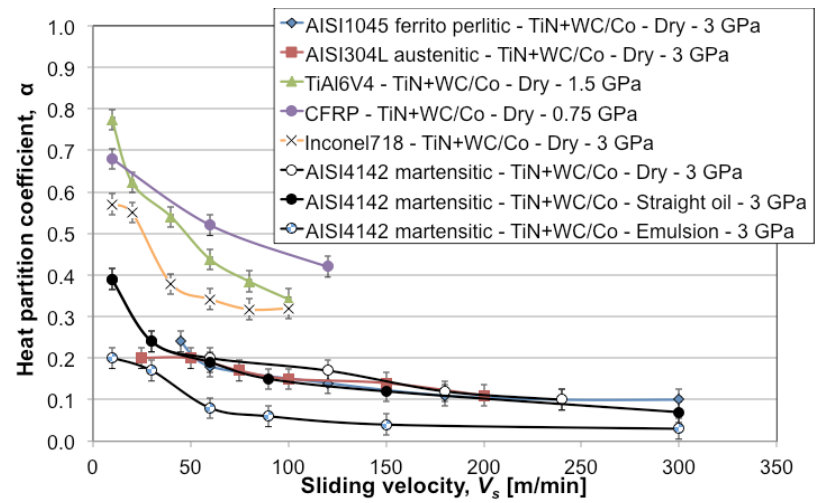

Fig. 3. Evolution of heat partition coefficient versus sliding velocity for various material pairs

result confirms the necessity to identify friction models depending on the sliding velocity. It can also be stated that ferrito-perlitic and austenitic steels lead to much higher friction coefficient compared to martensitic steels. Additionally, it can be observed that Inconel718 leads to rather low friction coefficient compared to any steels, and that Ti6Al4V induces even smaller values. Moreover, it is shown that CFRP exhibits so small apparent friction coefficient $(\sim 0.1)$ for high sliding velocities, that it can be considered as frictionless.

Fig. 3 also plots the evolution of heat partition coefficient a versus sliding velocity $V_{s}$. It is shown that it decreases significantly with sliding velocity as reported by [5]. Moreover, it reveals that the thermal conductivity of work materials is not a relevant parameter to estimate the heat partition coefficient. Indeed, it can be observed that the heat partition coefficient of an AISI 304L grade ( $(1-16 \mathrm{~W} /$ $\mathrm{mK}$ at $20^{\circ} \mathrm{C}$ ) leads to a similar heat partition coefficient compared to the one of an AISI 1045 grade $(1 \sim 47 \mathrm{~W} / \mathrm{mK}$ at $20^{\circ} \mathrm{C}$ ).

Regarding the influence of cutting fluids during the cutting of AISI 4142 martensitic steel, it is highlighted that the application of an emulsion leads to a large decrease of friction coefficient compared to a dry sliding contact in case of low sliding velocities, on the contrary to high sliding velocities. Additionally, it is shown that emulsion lowers the heat partition coefficient compared to a dry sliding contact for the whole range of velocity. Of course, the macroscopic cooling effect of emulsion on the cutting tool and the workpiece also remains and has to be considered when simulating a complete cutting process. The tribometer only provides thermal data at the tool-work material interface.

Regarding the influence of straight oil, it can be seen that it significantly reduces friction coefficient on the whole range of sliding velocity, whereas there is a slight action on heat partition coefficient.
Finally, it is revealed that, even if some authors have confirmed the benefit of cryogenic lubrication to improve wear resistance when cutting martensitic steels [14], based on those results, it is possible to claim that it cannot be attributed to the decrease of friction coefficient (at least in case of martensitic AISI 4142 work material). Its macroscopic cooling effect is probably more responsible for this improvement.

So it can be summarized that this tribometer has proved its capacity to discriminate the frictional influence of various parameters such as work material and lubrication for a large range of sliding velocities.

\section{Conclusions}

This paper has presented the performance of a newly developed tribometer, specialised for fast characterisation/ /identification of cutting tool-work material friction and heat partition. The tribometer has been applied on a wide spectrum of work materials and lubrication conditions. Large variation of friction coefficient and heat partition coefficient have been highlighted, which proves the interest of this tribometer to provide practical values for any kind of tool-work material pair.

\section{REFERENCES}

1. Coterell M., Byrne G. (2008) Dynamics of chip formation during orthogonal cutting of titanium alloy Ti6AI4V, CIRP Annals - Manufacturing Technology, 57(1): 93-96.

2. Ceretti E., Filice L., Umbrello D., Micari F. (2007) ALE Simulation of orthogonal cutting : a new approach to model heat transfer phenomena at the tool-chip interface, CIRP Annals - Manufacturing Technology, 56(1): 69-72.

3. Van Luttervelt C.A., Childs T.H.C., Jawahir I.S., Klocke F., Venuvinod P.K., Altintas Y., Armarego E., Dornfeld D., Grabec I., Leopold J., Lindstrom B., Lucca D., Obikawa T., Shirakashi Sato H. (1998) Present situation and future trends in modelling of machining operations - progress report of the CIRP working group 'Modelling of machining operations', CIRP Annals - Manufacturing Technologies, 47(2): 587-626.

4. Neugebauer R., Bouzakis K.D., Denkena B., Klocke F., Sterzing A., Tekkaya A.E., Wertheim R. (2011) Velocity effects in metal forming and machining processes, CIRP Annals - Manufacturing Technology, 60(1): 627-650

5. Grzesik W., Van Luttervelt C.A. (2001) An Investigation of the Thermal Effects in Orthogonal Cutting Associated with Multilayer Coatings, CIRP Annals - Manufacturing Technology, 50(1): 53-56.

6. Sölter J., Gulpak M. (2012) Heat partitioning in dry milling of steel, CIRP Annals - Manufacturing Technology, 61(1): 87-90.

7. Puls H., Klocke F., Lung D. (2012) A new experimental methodology to analyse the friction behaviour at the tool-chip interface in metal cutting, Production Engineering. 1-6.

8. Claudin C., Mondelin A., Rech J., Fromentin G. (2010) Effects of a straight oil on friction at the tool-work material interface in machining, International Journal of Machine Tools and Manufacture, 50: 681-688.

9. Rech J., Arrazola P.J., Claudin C., Courbon C., Pusavec F., Kopac J., (2013) Characterisation of friction and heat partition coefficients at the tool-work material interface in cutting, CIRP Annals, 62: 79-82.

10. Bonnet C., Valiorgue F., Rech J., Hamdi H. (2008) Improvement of the numerical modeling in orthogonal dry cutting of an AISI $316 \mathrm{~L}$ stainless steel by the introduction of a new friction model, CIRP Journal of Manufacturing Science and Technology, 1: 114-118.

11. Iraola J., Rech J., Valiorgue F., Arrazola P. (2012) Characterization of friction coefficient and heat partition coefficient between an austenitic steel AISI304L and a TiN coated carbide cutting tool, Machining Science and Technology, 16: 189-204.

12. Ben Abdelali H., Courbon C., Rech J., Ben Salem W., Dogui A., Kapsa P. (2011) Identification of a friction model at the Tool-Chip-Workpiece Interface in dry machining of a AISI 1045 steel with a TiN coated carbide tool, Journal of Tribology, 133(4): 042201.

13. Mondelin A., Claudin C., Rech J., Dumont F. (2011) Effects of lubrication mode on friction and heat partition coefficients at the tool-workmaterial interface in machining, Tribology Transactions, 54: 247-255.

14. Egana A., Rech J., Arrazola P.J. (2012) Characterization of friction and heat partition coefficients during machining of a TiAl6V4 titanium alloy and a cemented carbide, Tribology Transactions, 16: 189-204. 